\title{
Caracterização de concentrado protéico de folhas de mandioca obtido por precipitação com calor e ácido
}

Characterization of cassava leaf protein concentrate obtained by heat and acid precipitation

\author{
Cláudia de Fátima MODESTI ${ }^{1}$, Angelita Duarte CORRÊA ${ }^{1 *}$, Erasto Domingos de OLIVEIRA ${ }^{1}$, \\ Celeste Maria Patto de ABREU ${ }^{1}$, Custódio Donizete dos SANTOS ${ }^{1}$
}

\section{Resumo}

As folhas de mandioca apresentam um teor elevado de proteínas, todavia sua digestibilidade é baixa. A produção de concentrado protéico de folhas de mandioca (CPFM) permite a utilização das proteínas das folhas com um reduzido teor de fibras e melhor qualidade protéica. Neste trabalho, analisaram-se características químicas de CPFM obtidos por diferentes formas de precipitação, com calor e com ácido. Os CPFM praticamente não apresentaram diferenças na composição centesimal. O nível de proteína dos CPFM aumentou 57,72\% em comparação ao da farinha de folhas de mandioca (FFM). Os rendimentos de extração das proteínas também foram semelhantes para os CPFM. O teor de Fe dos CPFM foi mais elevado quando comparado com o da FFM. A FFM apresentou absorção de água e de óleo mais elevada que os CPFM, mas, entre os tipos de CPFM, os resultados foram semelhantes. A mínima solubilidade de nitrogênio da FFM e dos CPFM foi observada em pH entre 3 e 5. Verificou-se que a FFM apresentou uma capacidade de formação e estabilidade de espuma mais elevada que os CPFM. Tanto a FFM quanto os CPFM não apresentaram boa estabilidade de emulsão.

Palavras-chave: folha de mandioca; concentrado protéico; nutriente; digestibilidade protéica; propriedade funcional.

\begin{abstract}
Cassava leaves have a high content of protein of low digestibility. The production of cassava leaf protein concentrate (CLPC) enables cassava leaf protein to be used with a reduced fiber content and better protein quality. This work involved an investigation of the chemical characteristics of CLPC produced by different forms of precipitation, using heat and acid. No significant differences were found in the centesimal composition of the CLPC. The protein content in CLPC was $57.72 \%$ higher than in cassava leaf flour (CLF). Both types of CLPC precipitation also yielded similar protein concentrations. The CLPC Fe content was higher than that of the CLF. The CLF presented higher water and oil absorption than did CLPC, although the CLPC extracted by the two methods showed similar results. The lowest nitrogen solubility of CLF and CLPC was observed at a pH of 3 to 5 . The CLF exhibited greater foam forming ability and higher stability than the CLPC. Neither the CLF nor the CLPC presented good emulsion stability.

Keywords: cassava leaves; protein concentrate; nutrient; protein digestibility; functional property.
\end{abstract}

\section{Introdução}

As folhas verdes dos vegetais têm mostrado características favoráveis para servirem como fonte de proteínas, constituindo assim uma alternativa alimentar no combate à desnutrição, tanto de maneira indireta, sob a forma de rações animais, que servirão de alimento para o homem, quanto diretamente na dieta humana. No Brasil, alguns pesquisadores têm estudado as folhas de mandioca procurando uma possível alternativa para substituir alimentos convencionais, pois seu teor em proteínas, vitaminas e minerais é relativamente alto, quando comparado a hortaliças folhosas e grãos de cereais, além de apresentarem baixo custo e disponibilidade.

Apesar das folhas de mandioca apresentarem teor elevado de proteínas, a sua digestibilidade é baixa, devido provavelmente, ao alto teor de fibras e de polifenóis. A produção de concentrados protéicos de folhas (CPF) permite a utilização das proteínas foliares como alimento, contendo baixo teor de fibras e melhor qualidade nutritiva. Em muitas partes do mundo a extração de proteínas de folhas com a conseqüente obtenção

Recebido para publicação em 28/3/2006

Aceito para publicação em 18/7/2007 (001714)

Parte da dissertação do primeiro autor

${ }^{\prime}$ Departamento de Química, Universidade Federal de Lavras - UFLA,

CP 3037, CEP 37200-000, Lavras - MG, Brasil,

E-mail: angelita@ufla.br

*A quem a correspondência deve ser enviada de um concentrado protéico, praticamente sem fibras, vem sendo estudada ${ }^{2,5,10-12,20,29,32}$.

O interesse na pesquisa por novas fontes protéicas nãoconvencionais com o objetivo de estudar suas propriedades funcionais para aplicação na indústria alimentícia é cada vez maior. O concentrado protéico de folhas de mandioca (CPFM) é uma dessas fontes devido ao seu alto conteúdo de proteínas, perfil favorável de aminoácidos e propriedades funcionais. O CPFM tem se mostrado adequado como ingrediente funcional para aplicação em diversos alimentos ${ }^{11}$.

Diante disso, este trabalho teve como objetivo produzir CPFM sob duas formas de precipitação, pelo calor e pela adição de $\mathrm{HCl}$, caracterizando-os e analisando algumas propriedades funcionais.

\section{Material e métodos}

\subsection{Colheita das folhas de mandioca}

As folhas de mandioca (Manihot esculenta Crantz, cultivar Pão da China), maduras e frescas, cultivadas na região de Lavras - MG, foram colhidas pela manhã, em três repetições, no mês de janeiro (aos nove meses após o plantio) e transportadas rapidamente em sacos plásticos para o Laboratório de Bioquímica do Departamento de Química da UFLA. Parte das folhas foi utilizada para determinação de umidade, uma outra 
parte foi destinada à produção de farinha de folhas de mandioca (FFM), e as folhas restantes para a obtenção do concentrado protéico de folhas de mandioca (CPFM).

\subsection{Preparo da farinha de folhas de mandioca}

As folhas de mandioca foram lavadas com água corrente e água destilada, colocadas para secar à sombra, em bandejas de papel, em recinto fechado e arejado, à temperatura ambiente por seis dias. Em seguida, foram levadas à estufa a $30{ }^{\circ} \mathrm{C}$ por quatro horas, sem os pecíolos, trituradas em moinho e armazenadas em frascos hermeticamente fechados.

\subsection{Obtenção do concentrado protéico de folhas de mandioca}

As folhas de mandioca foram lavadas com água corrente e água destilada, colocadas para escorrer e pesadas. Em seguida, foram picadas e trituradas em um liquidificador com uma solução aquosa de metabissulfito de sódio $(5 \mathrm{mg}$ de metabissulfito de sódio.100 $\mathrm{mL}^{-1}$ ) na proporção de 1:4, em velocidade máxima por 2 minutos. Dessa forma, obteve-se um homogeinato que foi filtrado em tecido de algodão, separando-se o suco verde do resíduo fibroso (RF). Este resíduo foi submetido a uma reextração, nas mesmas condições. O RF foi colocado sobre um papel, seco em estufa com circulação de ar em temperatura de $\pm 36{ }^{\circ} \mathrm{C}$, triturado em gral e armazenado em frascos hermeticamente fechados. O suco verde da reextração foi reunido com o primeiro, sendo registrado seu pH e sua temperatura. Foi então colocado em banho-maria a $80{ }^{\circ} \mathrm{C}$ por 15 minutos, e o precipitado formado foi resfriado em banho de gelo. Esse precipitado foi denominado concentrado protéico de folhas de mandioca precipitado com calor (CPFMC). Uma segunda extração das proteínas foi feita nas mesmas condições, diferindo apenas na forma de precipitação, na qual se empregou $\mathrm{HCl}$ concentrado, abaixando o $\mathrm{pH}$ até 4,0 com uso do pHmetro sob agitação constante. Depois de um período de repouso, o precipitado formado foi denominado concentrado protéico de folhas de mandioca precipitado com ácido (CPFMA). Esses processos de extrações foram realizados em três repetições. Os CPFM foram centrifugados, a 1863 x g por 15 minutos, e seus sobrenadantes descartados. Foram congelados em freezer e liofilizados até peso constante. Em seguida, foram triturados em gral e armazenados em frascos hermeticamente fechados.

\subsection{Análises}

Para as determinações da umidade, proteína bruta ( $\mathrm{N} \mathrm{x}$ 6,25), extrato etéreo e cinzas empregaram-se as técnicas descritas pela $\mathrm{AOAC}^{3}$. A determinação de fibra detergente neutro (FDN) foi realizada conforme proposto por Van Soest e Wine, descrito por SILVA ${ }^{31}$. Para a análise de digestibilidade protéica in vitro foi usado o método de AKESON e STAHMANN ${ }^{1}$. A composição mineral foi determinada segundo MALAVOLTA, VITTI e OLIVEIRA ${ }^{18}$, sendo o $\mathrm{P}$ e o $\mathrm{S}$ determinados por colorimetria, o K por fotometria de chama, e, o Ca, Mg, Cu, Mn, $\mathrm{Zn}$ e Fe por espectrofotometria de absorção atômica.

Para as propriedades funcionais utilizou-se para análise de absorção de água e óleo o método de OKEZIE e BELLO ${ }^{22}$ e para a solubilidade de nitrogênio o de BEUCHAT ${ }^{4}$. A determinação do volume de espuma foi realizada conforme proposto por WANG, CABALLERO-CORBOBA e SGARBIERI ${ }^{33}$ e a estabilidade de emulsão de acordo com o método de OKEZIE e BELLO ${ }^{22}$.

\section{Resultados e discussão}

\subsection{Composição centesimal e rendimento de extração}

Na Tabela 1, estão apresentados os resultados da composição centesimal da farinha de folhas de mandioca (FFM), dos concentrados protéicos de folhas de mandioca (CPFM) e dos resíduos fibrosos (RF).

Os resultados da composição centesimal da FFM estão dentro da faixa de variação citada na literatura ${ }^{17,23,25}$, exceto os de FDN (21,40 g. $\left.100 \mathrm{~g}^{-1} \mathrm{MS}\right)$, cujos teores foram inferiores aos de CORRÊA et al. ${ }^{8}$ e REED et al. ${ }^{28}$, que variaram de 32,82 a 35,40 g. $100 \mathrm{~g}^{-1}$ MS. A FFM estudada apresentou teor mais elevado em proteínas que outras hortaliças convencionais, como as de taioba (27,59 g. $\left.100 \mathrm{~g}^{-1} \mathrm{MS}\right)$, segundo PINTO et al. ${ }^{26}$, e as de couve (30,85 g. $\left.100 \mathrm{~g}^{-1} \mathrm{MS}\right)$, de acordo com FONSECA et al. ${ }^{14}$.

Os dois métodos de precipitação utilizados para a obtenção do CPFM praticamente não acarretaram diferenças na composição centesimal (Tabela 1). O nível de proteína do CPFM foi em média 57,22\% superior ao da FFM. Os CPFM apresentaram um teor protéico e de extrato etéreo acima do observado por HEINEMANN et al. ${ }^{16}$ e MOLINA ${ }^{20}$, já o teor de cinzas foi inferior. Constatou-se que, ao se produzirem os CPFM, a quantidade de fibras foi acentuadamente reduzida: para o CPFMA, foi encontrado 1,64 g. $100 \mathrm{~g}^{-1} \mathrm{MS}$ e para o CPFMC, não foi detectada sua presença.

Tabela 1. Composição centesimal (g. $\left.100 \mathrm{~g}^{-1} \mathrm{MS}\right)^{1}$ da FFM, dos CPFM e dos RF.

\begin{tabular}{|c|c|c|c|c|c|}
\hline Amostras $^{2}$ & Proteína bruta & Extrato etéreo & Cinzas & $\mathrm{FDN}^{3}$ & $\mathrm{ENN}^{4}$ \\
\hline FFM & $34 \pm 1,78$ & $12 \pm 1,35$ & $6,52 \pm 0,31$ & $21,40 \pm 0,93$ & $25 \pm 2,36$ \\
\hline CPFMC & $54 \pm 2,50$ & $17 \pm 1,05$ & $2,19 \pm 0,12$ & $\mathrm{ND}^{5}$ & $26 \pm 2,81$ \\
\hline CPFMA & $54 \pm 1,74$ & $17,28 \pm 0,30$ & $2,17 \pm 0,23$ & $1,64 \pm 0,63$ & $24 \pm 1,96$ \\
\hline $\mathrm{RFC}$ & $19,77 \pm 0,40$ & $6,97 \pm 0,25$ & $5,70 \pm 0,28$ & $47,94 \pm 0,88$ & $19,62 \pm 0,62$ \\
\hline RFA & $19,07 \pm 0,36$ & $6,68 \pm 0,28$ & $5,59 \pm 0,05$ & $41 \pm 1,11$ & $27,51 \pm 0,87$ \\
\hline
\end{tabular}

Umidade das folhas de mandioca, da FFM, do RFC e do RFA: 74,57 $\pm 0,69$ g. $100 \mathrm{~g}^{-1} ; 9,46 \pm 0,56$ g. $100 \mathrm{~g}^{-1}, 10,64 \pm 0,45$ g.100 g ${ }^{-1}$ e $10,65 \pm 0,28$ g. $100 \mathrm{~g}^{-1}$, respectivamente; ${ }^{1}$ MS: Matéria seca; média de 3 repetições \pm desvio padrão; ${ }^{2} \mathrm{FFM}$ : farinha de folhas de mandioca; CPFMC: concentrado protéico de folhas de mandioca precipitado com calor; CPFMA: concentrado protéico de folhas de mandioca precipitado com ácido; RFC: resíduo fibroso da precipitação com calor; RFA: resíduo fibroso da precipitação com ácido; ${ }^{3} \mathrm{FDN}$ : fibra detergente neutro; ${ }^{4} \mathrm{ENN}$ : extrato não nitrogenado; ${ }^{5} \mathrm{ND}$ : não detectado. 
Os RF ainda contêm uma fração considerável de proteína bruta (19,42 g. $100 \mathrm{~g}^{-1} \mathrm{MS}$ ), constituindo assim uma boa fonte de alimentação alternativa para os ruminantes. Já o teor de FDN dos RF, como era esperado, foi bem elevado (47,94 g. $100 \mathrm{~g}^{-1}$ MS para o RFC e 41,15 g. $100 \mathrm{~g}^{-1}$ MS para o RFA).

Os rendimentos de extração das proteínas de folhas de mandioca estão registrados na Tabela 2 . Também nesses resultados os dois métodos de precipitação utilizados para a obtenção dos CPFM praticamente não mostraram diferenças.

Tabela 2. Rendimento de extração das proteínas de folhas de mandioca.

\begin{tabular}{lrcc}
\hline \multicolumn{1}{c}{ Amostras } & Peso seco $(g)$ & \multicolumn{2}{c}{ Rendimento } \\
\cline { 3 - 4 } & & Peso (\%) & Proteína (\%) \\
\hline Folhas frescas $^{1}$ & $101,72 \pm 0,70$ & - & - \\
CPFMC $^{2}$ & $32,00 \pm 1,24$ & $31,35 \pm 1,25$ & $54,58 \pm 1,87$ \\
CPFMA $^{3}$ & $33,74 \pm 1,10$ & $33,21 \pm 1,10$ & $58,00 \pm 2,91$ \\
\hline
\end{tabular}

Média de 3 repetições \pm desvio padrão; ${ }^{1} 400 \mathrm{~g}$ de folhas frescas com teor de umidade de 74,57 g. $100 \mathrm{~g}^{-1} \pm 0,69 ;{ }^{2} \mathrm{CPFMC}$ : concentrado protéico de folhas de mandioca precipitado com calor; $\mathrm{e}^{3} \mathrm{CPFMA}$ : concentrado protéico de folhas de mandioca precipitado com ácido.

O rendimento médio em peso foi de $32,28 \%$, e está bem próximo do encontrado por $\mathrm{CHAVES}^{5}$, que também estudou a influência das condições de precipitação no rendimento de extração das proteínas de folhas de mandioca. Para a extração das proteínas das folhas, ele utilizou uma máquina de moer carne e adicionou uma solução de $\mathrm{NaOH} 0,05 \mathrm{~N}$, em seguida, para a precipitação, utilizou calor a $85^{\circ} \mathrm{C}$ encontrando $30,40 \%$ de rendimento em peso. Já MOLINA ${ }^{20}$, utilizando um liquidificador para a extração das proteínas com solução de $\mathrm{NaOH}$ e precipitando-as com abaixamento do $\mathrm{pH}$ a 4,0 seguido de aquecimento a $85{ }^{\circ} \mathrm{C}$ (termogoagulação ácida), observou um rendimento $11,30 \%$, inferior ao deste trabalho.

O rendimento de extração das proteínas foi de $54,58 \%$ para o CPFMC e de 58,00\% para o CPFMA. Rendimento próximo de $51,80 \%$ foi observado por CHAVES $^{5}$ para a precipitação com calor a $85{ }^{\circ} \mathrm{C}$. Um rendimento de $20,84 \%$, bem inferior ao deste trabalho, foi encontrado por MOLINA ${ }^{20}$ para CPFM obtido por abaixamento do $\mathrm{pH}$ até 4,0 seguido de aquecimento a $85{ }^{\circ} \mathrm{C}$, e de $14,97 \%$ para o CPFM obtido por precipitação isoelétrica, um processo que utiliza apenas o abaixamento do $\mathrm{pH}$ até 4,0 sem a injeção de calor.

\subsection{Composição mineral}

Na Tabela 3, encontram-se os resultados das análises de minerais da FFM, dos CPFM e dos RF. Os teores de P, K,
$\mathrm{Ca}, \mathrm{Mg}, \mathrm{S}, \mathrm{Cu}, \mathrm{Mn}$ e Fe da FFM estão dentro da faixa relatada pela literatura ${ }^{6,8,19,34}$. O teor de Zn da FFM (93,38 mg. $\mathrm{kg}^{-1}$ MS) se apresentou mais elevado ao de CHAVEZ et al. ${ }^{6}$ e de WOBETO et al. ${ }^{34}$, cujos teores variaram de $35,8 \mathrm{mg} . \mathrm{kg}^{-1} \mathrm{MS}$ a $67,10 \mathrm{mg} \cdot \mathrm{kg}^{-1} \mathrm{MS}$.

Foi observado que os níveis da maioria desses minerais reduziram ao se produzir os CPFM, exceto o de $\mathrm{S}$ e Fe. O nível de S provavelmente aumentou porque esse mineral está presente em aminoácidos sulfurados. O CPFMC teve um aumento de $91,51 \%$ e o CPFMA de $56,91 \%$ no teor de Fe quando comparado ao da FFM.

A deficiência de Fe é uma das causas mais comuns de anemia nutricional no homem ${ }^{15,21}$. Portanto, o aumento do teor de Fe nos CPFM sugere que eles podem suprir ainda mais uma deficiência desse mineral no organismo. Quando se compara o teor de Fe da FFM $\left(88,73\right.$ mg. $\mathrm{kg}^{-1}$ matéria integral) com fontes convencionais ${ }^{15}$, como por exemplo, a gema de ovo $\left(58,70 \mathrm{mg} . \mathrm{kg}^{-1}\right)$ observa-se que ela é rica em Fe. Todavia, deve-se observar que o ferro da gema é $100 \%$ aproveitado pelo organismo, enquanto que nos alimentos de origem vegetal o aproveitamento varia de 15 a $30 \%{ }^{15}$. Os RF também apresentaram elevados teores de Fe, todavia, segundo FRANCO $^{15}$, grandes quantidades de fibras podem reduzir a absorção desse mineral.

\subsection{Digestibilidade protéica}

Nas duas formas de precipitação utilizadas para a obtenção dos CPFM, praticamente não foram verificadas diferenças na digestibilidade protéica, sendo encontrado em média 54,93\%. A digestibilidade do CPFM aumentou em média 93,55\% em comparação com a da FFM (Tabela 4). SALGADO e SANTOS ${ }^{29}$ determinaram a digestibilidade protéica de uma dieta de CPFM precipitado com calor (entre 60 e $65{ }^{\circ} \mathrm{C}$ ) contendo $10 \%$ em proteína administrada a ratos e encontraram 48,50\%. Já MOLINA ${ }^{20}$ encontrou uma digestibilidade protéica in vitro de $80,00 \%$ para o CPFM precipitado com ácido ( $\mathrm{pH}$ 4,0 seguido de aquecimento a

Tabela 4. Digestibilidade protéica in vitro da FFM e dos CPFM.

\begin{tabular}{cc}
\hline Amostras $^{1}$ & ${\text { Digestibilidade protéica in } \text { vitro }^{2}(\%)}^{28,38 \pm 3,09}$ \\
FFM & $55,82 \pm 1,89$ \\
CPFMC & $54,03 \pm 2,51$ \\
\hline
\end{tabular}

Média de 3 repetições \pm desvio padrão; ${ }^{1} \mathrm{FFM}$ : farinha de folhas de mandioca; CPFMC: concentrado protéico de folhas de mandioca precipitado com calor; CPFMA: concentrado protéico de folhas de mandioca precipitado com ácido; e ${ }^{2}$ Valores corrigidos para caseína, considerada $100 \%$ digerível.

Tabela 3. Teores de minerais da FFM, dos CPFM e dos RF.

\begin{tabular}{|c|c|c|c|c|c|c|c|c|c|}
\hline \multirow[t]{2}{*}{ Amostras $^{1}$} & \multicolumn{5}{|c|}{ (g.100 g $\left.\mathrm{g}^{-1} \mathrm{MS}\right)$} & \multicolumn{4}{|c|}{ (mg.kg-1 MS) } \\
\hline & $\mathrm{P}$ & $\mathrm{K}$ & $\mathrm{Ca}$ & $\mathrm{Mg}$ & $\mathrm{S}$ & $\mathrm{Cu}$ & Mn & $\mathrm{Zn}$ & $\mathrm{Fe}$ \\
\hline FFM & $0,29 \pm 0,01$ & $1,59 \pm 0,03$ & $1,09 \pm 0,06$ & $0,32 \pm 0,03$ & $0,29 \pm 0,01$ & $10,71 \pm 0,25$ & $188 \pm 1,27$ & $93 \pm 1,33$ & $98,40 \pm 2,60$ \\
\hline CPFMC & $0,22 \pm 0,01$ & $0,15 \pm 0,00$ & $0,38 \pm 0,04$ & $0,07 \pm 0,01$ & $0,56 \pm 0,04$ & $9,80 \pm 0,50$ & $60 \pm 3,31$ & $91,00 \pm 0,28$ & $188,45 \pm 1,76$ \\
\hline CPFMA & $0,32 \pm 0,02$ & $0,13 \pm 0,03$ & $0,37 \pm 0,01$ & $0,04 \pm 0,00$ & $0,58 \pm 0,05$ & $16,10 \pm 0,75$ & $27 \pm 2,44$ & $40,20 \pm 1,23$ & $154,40 \pm 0,28$ \\
\hline $\mathrm{RFC}$ & $0,13 \pm 0,00$ & $0,49 \pm 0,03$ & $1,64 \pm 0,06$ & $0,36 \pm 0,01$ & $0,13 \pm 0,00$ & $4,22 \pm 0,32$ & $444 \pm 2,61$ & $97,97 \pm 1,82$ & $47,93 \pm 1,63$ \\
\hline RFA & $0,13 \pm 0,00$ & $0,47 \pm 0,01$ & $1,60 \pm 0,04$ & $0,36 \pm 0,00$ & $0,13 \pm 0,00$ & $5,32 \pm 0,08$ & $397 \pm 4,18$ & $110,98 \pm 4,08$ & $49,61 \pm 2,56$ \\
\hline
\end{tabular}

folhas de mandiça \pm deswandioca precipitado 
$\left.85^{\circ} \mathrm{C}\right)$. Essas diferenças devem estar provavelmente relacionadas ao processamento empregado na obtenção do CPFM, além da cultivar, idade da planta e maturidade das folhas.

\subsection{Propriedades funcionais}

A absorção de água da FFM (667,00\%) foi maior que a dos CPFM (367,00\%), possivelmente devido à maior presença de grupos hidrofílicos na FFM capazes de se ligar à água (Tabela 5). FASUYI e ALETOR ${ }^{12}$ encontraram uma média de 409,00\% de absorção de água para FFM de quatro variedades e para os CPFM precipitados com calor a uma temperatura entre $80{ }^{\circ} \mathrm{C}$ e $90{ }^{\circ} \mathrm{C}$ encontraram um porcentual que variou de 118,00 a $225,50 \%$ utilizando uma metodologia semelhante à deste trabalho.

Tanto a FFM, quanto os CPFM são indicados para atuar como ingredientes em alimentos viscosos como, por exemplo, em sopas e molhos, devido a sua alta porcentagem de absorção de água ${ }^{12}$.

A absorção de óleo também foi maior na FFM (107,20\%) que no CPFMC (53,60\%) e no CPFMA (48,00\%) (Tabela 5). FASUYI e ALETOR ${ }^{12}$ encontraram uma absorção de óleo, para FFM, cujas folhas foram secas ao sol, de $56,80 \%$, e uma variação de 19,20 a 40,80\% para o CPFMC. A absorção de óleo foi maior nas amostras do presente estudo. Essas diferenças estão provavelmente relacionadas à utilização de diferentes metodologias para realização do ensaio de absorção de óleo, método de obtenção dos CPF e são também inerentes aos cultivares.

Tabela 5. Absorção de água e de óleo da FFM, do CPFMC e do CPFMA.

\begin{tabular}{ccc}
\hline Amostras $^{1}$ & Absorção de água (\%) & Absorção de óleo (\%) \\
\hline FFM & $667,00 \pm 0,58$ & $107,20 \pm 0,3$ \\
CPFMC & $367,00 \pm 0,58$ & $53,60 \pm 0,3$ \\
CPFMA & $367,00 \pm 0,58$ & $48,00 \pm 0,2$
\end{tabular}

Média de 3 repetições \pm desvio padrão; ${ }^{1} \mathrm{FFM}$ : farinha de folhas de mandioca; CPFMC: concentrado protéico de folhas de mandioca precipitado com calor; e CPFMA: concentrado protéico de folhas de mandioca precipitado com ácido.

A diminuição da absorção de óleo dos CPFM em comparação com a da FFM pode estar relacionada à hipótese de que a maior porcentagem de fibras e a presença de outros fatores além das proteínas, capazes de se ligarem ao óleo, são responsáveis pela maior absorção ${ }^{27}$.

Observa-se na Figura 1 que ocorreram variações nas porcentagens de solubilidade de nitrogênio em função dos pH para cada amostra. A menor solubilidade de nitrogênio da FFM foi observada entre o pH 3 e 4 (47,39 e 48,22\%, respectivamente) e a maior em pH 9 (88,73\%). FASUYI e ALETOR ${ }^{12}$ observaram que a menor solubilidade de nitrogênio da FFM foi entre $\mathrm{pH} 4$ e 5, e a maior em $\mathrm{pH}$ alcalino ( $\mathrm{pH} \mathrm{12).}$

Observou-se uma menor solubilidade de nitrogênio do CPFMC nos pH 3, 4 e 5 (9,34, 9,50 e 9,49\%, respectivamente) e do CPFMA no pH 3 (6,71\%). A literatura revela uma menor solubilidade da proteína do CPFM obtido por termocoagulação ácida entre $\mathrm{pH} 2$ e $6^{20}$ e para CPFMC entre $\mathrm{pH} 4$ e $6^{12}$. Assim como no trabalho de MOLINA ${ }^{20}$, os dois CPFM do presente es-



Figura 1. Solubilidade de nitrogênio em diferentes $\mathrm{pH}$ da farinha de folhas de mandioca (FFM), do concentrado protéico de folhas de mandioca precipitado com calor (CPFMC) e do concentrado protéico de folhas de mandioca precipitado com ácido (CPMFA).

tudo apresentaram maior porcentagem em pH alcalino ( $\mathrm{pH}$ 9). O ponto isoelétrico das proteínas vegetais está entre pH 3 e 5, portanto justifica a baixa solubilidade encontrada próxima a esta faixa de $\mathrm{pH}$. MOLINA ${ }^{20}$ verificou uma solubilidade de nitrogênio do CPFM obtido por termocoagulação ácida semelhante a do presente trabalho, com valores inferiores a $20 \%$ em uma faixa de $\mathrm{pH}$ que variou de 2 a 12. A solubilidade de nitrogênio diminuiu provavelmente devido à desnaturação das proteínas e possivelmente essa seria uma das explicações de uma menor solubilidade dos CPFM em relação à da FFM.

Assim como no trabalho de FASUYI e ALETOR ${ }^{12}$, a FFM mostrou uma elevada solubilidade em pH 9 (88,73\%), seguida pelo pH $2(59,49 \%)$ e, portanto, seria provavelmente mais indicada para uma possível aplicação na produção de massas, sopas, produtos de padaria e confeitaria e em produtos ácidos como bebidas carbonatadas ricas em proteínas ${ }^{24}$.

Na Tabela 6, está registrado o volume de espuma da FFM, do CPFMC e do CPFMA após 30, 60 e 120 minutos em repouso. A FFM apresentou $78 \%$ de espuma aos 30 minutos após a agitação, havendo uma redução desse volume para $64 \%$ que se manteve até os 120 minutos. Verificou-se que a FFM possuiu uma capacidade de formação e estabilidade de espuma mais elevada que a dos CPFM.

Tabela 6. Volume de espuma da FFM, do CPFMC e do CPFMA.

\begin{tabular}{lrrr}
\hline Amostras $^{1}$ & \multicolumn{3}{c}{ Volume de espuma (\%) após } \\
\cline { 2 - 4 } & 30 minutos & 60 minutos & 120 minutos \\
\hline FFM & $78,57 \pm 5,15$ & $64,29 \pm 4,12$ & $64,29 \pm 4,12$ \\
CPFMC & $46,00 \pm 2,06$ & $10,00 \pm 4,77$ & $0,00 \pm 0,00$ \\
CPFMA & $0,00 \pm 0,00$ & $0,00 \pm 0,00$ & $0,00 \pm 0,00$ \\
\hline
\end{tabular}

Média de 3 repetições \pm desvio padrão; ${ }^{1} \mathrm{FFM}$ : farinha de folhas de mandioca; $\mathrm{CPFMC}$ : concentrado protéico de folhas de mandioca precipitado com calor; e CPFMA: concentrado protéico de folhas de mandioca precipitado com ácido.

O CPFMC apresentou $46 \%$ de espuma formada aos 30 minutos; aos 60 minutos esse valor foi reduzido para $10 \%$, sendo que aos 120 minutos não havia mais espuma. Segundo SANGRONIS, MACHADO e $\mathrm{CAVA}^{30}$, o $\mathrm{pH}$ afeta a capacidade 
espumante e esse efeito foi claramente mostrado pelo CPFMA que não apresentou formação de espuma durante e após a agitação, devido ao pH 4,0 de precipitação usado na obtenção do concentrado. EPSTEIN ${ }^{9}$ também não observou formação de espuma no isolado protéico de feijão bravo obtido pelo abaixamento de $\mathrm{pH}$ a 4,5, mostrando que de fato o $\mathrm{pH}$ afeta a capacidade de formação de espuma em alimentos.

Uma outra possível explicação para a menor quantidade de espuma formada nos CPFM seria a maior porcentagem de lipídeos no concentrado (17,39 g.100 $\left.\mathrm{g}^{-1} \mathrm{MS}\right)$ em relação à FFM (12,52 g. $100 \mathrm{~g}^{-1}$ MS). Segundo FENNEMA ${ }^{13}$, a presença de lipídeos em excesso pode reduzir a formação e a estabilidade de espuma devido à alteração da expansão da proteína à interface e enfraquecimento ou rompimento das forças coesivas necessárias entre a camada de proteína em torno dos glóbulos de ar, tendo por conseqüência o colapso de espuma.

As espumas alimentícias podem ser definidas como uma dispersão de glóbulos de gás, geralmente o ar, separados por uma suspensão de proteínas que reduz a tensão superficial entre o ar e o líquido, facilitando a deformação do segundo e assim se formam filmes estruturais em volta das gotas de ar, prendendo-o e formando bolhas. A capacidade de uma proteína em formar espuma refere-se à expansão de volume da dispersão protéica com a incorporação de ar por batimento ou agitação. Já a emulsão pode ser definida como sendo um sistema com duas fases líquidas imiscíveis, dispersas uma na outra, em forma de pequenas gotículas. A capacidade de uma proteína de formar emulsões depende da diminuição da tensão superficial entre as fases imiscíveis. A estabilidade de emulsão mede a capacidade das proteínas de manter a mistura em uma força homogênea, quando submetida à ação de uma força ou calor ${ }^{7,13}$.

Na FFM, foram observados uma redução do volume de espuma e um aumento do volume de óleo, sendo que a quantidade de água se manteve após 2 horas e em seguida ocorreu um aumento de 10\% (Tabela 7). Nos CPFM, o volume de espuma reduziu e o de óleo e água aumentou após 6 horas, diferindo apenas nos volumes registrados para cada CPFM. Tanto a FFM quanto os CPFM não apresentaram boa estabilidade de emulsão.

Constatou-se que há uma grande dificuldade em se comparar os resultados das propriedades funcionais com os da

Tabela 7. Estabilidade de emulsão da FFM, do CPFMC e do CPFMA

\begin{tabular}{lcrrr}
\hline Parâmetros & $\begin{array}{c}\text { Tempo } \\
\text { (horas) }\end{array}$ & FFM $^{1}$ & CPFMC $^{2}$ & CPFMA $^{3}$ \\
\hline Espuma (mL) & 0,5 & $11,50 \pm 0,28$ & $17,00 \pm 0,87$ & $10,00 \pm 0,29$ \\
& 2 & $11,00 \pm 0,28$ & $13,00 \pm 0,87$ & $8,59 \pm 0,00$ \\
& 6 & $10,00 \pm 0,29$ & $11,50 \pm 0,00$ & $8,50 \pm 0,28$ \\
Óleo (mL) & 0,5 & $3,50 \pm 0,28$ & $0,00 \pm 0,00$ & $4,09 \pm 0,58$ \\
& 2 & $4,00 \pm 0,28$ & $1,00 \pm 0,00$ & $4,50 \pm 0,87$ \\
Fase aquosa & 0,5 & $5,00 \pm 0,58$ & $3,00 \pm 0,00$ & $6,00 \pm 0,00$ \\
(mL) & 2 & $5,00 \pm 0,58$ & $6,00 \pm 0,00$ & $7,00 \pm 0,00$ \\
& 6 & $5,50 \pm 0,58$ & $7,00 \pm 0,58$ & $7,00 \pm 0,50$ \\
\hline
\end{tabular}

Média de 3 repetições \pm desvio padrão; ${ }^{\mathrm{FFM}}$ : farinha de folhas de mandioca; ${ }^{2} \mathrm{CPFMC}$ : concentrado protéico de folhas de mandioca precipitado com calor; $\mathrm{e}^{3} \mathrm{CPFMA}$ : concentrado protéico de folhas de mandioca precipitado com ácido. literatura devido à falta de padronização das metodologias analíticas usadas na determinação desses parâmetros, além de estarem associadas à influência de diversos fatores como $\mathrm{pH}$, temperatura, tipo de aparelho utilizado e as próprias características das proteínas.

\section{Conclusões}

Concluiu-se que as duas diferentes formas de precipitação (calor e ácido) utilizadas para a obtenção de concentrado protéico de folhas de mandioca (CPFM) não apresentaram diferenças nos resultados em relação aos constituintes químicos analisados.

A obtenção dos CPFM acarretou um aumento médio de $57,72 \%$ no teor protéico e de $93,55 \%$ na digestibilidade protéica.

Em relação às propriedades funcionais os CPFM apresentaram boa capacidade de absorção de água e de óleo, baixa solubilidade de nitrogênio e má estabilidade de emulsão e formação de espuma.

\section{Agradecimentos}

À CAPES e ao CNPq pela concessão das bolsas de mestrado e iniciação científica, respectivamente.

\section{Referências bibliográficas}

1. AKESON, W. R.; STAHMANN, M. A. A pepsin pancreatin digest index of protein quality evaluation. Journal of Nutrition, Bethesda, v. 83, p. 257-261, 1964.

2. ALETOR, O.; OSHOdI, A. A.; IPINMOROTO, K. Chemical composition of commom leaf vegetables and functional properties of their leaf protein concentrates. Food Chemistry, Oxford, v. 78, p. 63-68, 2002.

3. ASSOCIATION OF OFFICIAL ANALYTICAL CHEMISTS. Official methods of analysis of the association of the analytical chemists. 16. ed. Washington, 1995.

4. BEUCHAT, L. R. Functional and eletrophoretic characteristics of succinylated peanut flour protein. Journal of Agricultural. and Food Chemistry, Washington, v. 25, n. 2, 1977.

5. CHAVES, J. G. Extrato protéico das folhas de mandioca. Informe Agropecuário, Belo Horizonte, v. 13, n. 145, p. 47-52, 1987.

6. CHAVEZ, A. L.; BEDOYA, J. M.; SÁNCHEZ, T.; IGLESIAS, C.; CEBALLOS, H.; ROCA, W. Iron, carotene, and ascorbic acid in cassava roots and leaves. Food and Nutrition Bulletin, Tokyo, v. 21, n. 4 , p. $410-413,2000$.

7. Cheftel, J. C.; CUQ, J. L.; LORIEnT, D. Proteínas alimentarias. Bioquímica. Propriedades funcionales. Valor nutritivo. Modificaciones químicas. Zagaroza: Editora Acribia, 1989. 346 p.

8. CORRÊA, A. D. et al. Remoção de polifenóis da farinha de folhas de mandioca. Ciência Tecnologia de Alimentos, Campinas, v. 24, n. 2, p. 159-164, 2004.

9. EPSTEIN, M. Caracterização química do feijão branco (Canavalia brasiliensis, mart.) e propriedades nutricionais e funcionais do seu isolado protéico. Viçosa-MG, 1985, 83 p. Tese (Doutorado). Universidade Federal de Viçosa (UFV). 
10. FASAKIN, E. A. Nutrient quality of leaf protein concentrates produced from water fern (Azolla africana Desv) e duckweed (Spirodela polyrrhiza L. Schleiden). Bioresource Technology, Oxford, v. 69, n. 2, p. 185-187, 1999.

11. FASUYI, O. A. Nutritional evaluation of cassava (Manihot esculenta, Crantz) leaf protein concentrates (CLPC) as alternative protein sources in rat assay. Paskitan Journal of Nutrition, Faisalabad, v. 4, p. 50-56, 2005.

12. FASUYI, O. A.; ALETOR, V. A. Varietal composition and funtional properties of cassava (Manihot esculenta, Crantz) leaf meal and leaf protein concentrates. Paskitan Journal of Nutrition, Faisalabad, v. 1, p. 43-49, 2005.

13. FENNEMA, O. R. Guímica de los alimentos. Zaragoza: Acribia, 1993. $1095 \mathrm{p}$.

14. FONSECA, S. V. et al. Folhas verdes de feijão na alimentação humana: avaliação sensorial, adubação nitrogenada e desfolhamento. Bragantia, Campinas, v. 1, n. 2, maio/ ago.,2002.

15. FRANCO, G. V. E. Tabela de composição química dos alimentos, 9 ed. São Paulo: Atheneu, 2000. 307 p.

16. HEINEMANN, R. B. et al. Valor nutricional de farinha de trigo combinada com concentrado protéico de folha de mandioca. Revista de Nutrição de Campinas, Campinas, v. 11, n. 1, p. 51-57, 1998.

17. MADRUGA, M. S.; CÂMARA, F. S. The chemical composition of multimistura as a food supplement. Food Chemistry, Oxford, v.68, p. 41-44, 2000.

18. Malavolta, E., VITTI, G. C.; Oliveira, S. A. Avaliação do estado nutricional das plantas, Piracicaba: Potafos, 1997. $319 \mathrm{p}$.

19. MELO, D. S. et al. Efeitos da farinha de folhas de mandioca sobre a peroxidação lipídica, o perfil lipídico sangüíneo e o peso do fígado de ratos. Ciência Agrotecnologia, Lavras, v. 31, n. 2, p. 420-428, 2007.

20. MOLINA, C. R. Caracterização bioquímica e nutricional de concentrado protéico de folhas de mandioca (Manihot esculenta Crantz) obtido por ultrafiltração. Campinas - SP. 1989. 199 p. Tese (Doutorado em Engenharia de Alimentos) Universidade Estadual de Campinas (UNICAMP).

21. MOTTA, J. S. et al. A farinha da folha de mandioca: uma alternativa como complemento alimentar. Mandioca em foco, Cruz das Almas, v. 4, p. 1-2, 1994.

22. OKEZIE, B. O.; BELLO, A. B. Physicochemical and functional properties of winged bean flour and isolate compared with soy isolate. Journal of Food Science, Chicago, v. 53, n. 2, p. 450-454, Mar./Apr.1988.
23. ORTEGA-Flores, C. I.; COSTA, M. A. I.; CEREDA, M. P.; PENTEADO, M. V. C. Avaliação da qualidade protéica da folha desidratada de mandioca (Manihot esculenta Crantz). Sociedade Brasileira de Alimentos e Nutrição, São Paulo, v. 25, p. 47-59, jun., 2003.

24. OSHODI, A. A.; EKPERIGIN, M. M. Functional properties of pigeon pea (Cajanus cajan) flour. Food Chemistry, Oxford, v. 34, n. 3, p. 187-191, 1989.

25. PHUC, B. H. N.; OGLE, B.; LINDBERG J. E. Effect of replacing soybean protein with cassava leaf protein in cassava root meals based diets for growing pigs on digestibility and $\mathrm{N}$ retention. Animal Feed Science and Technology, Amsterdam, v. 83, p. 223235, 2000.

26. PINTO, N. A. V. D. et al. Variabilidade da composição centesimal, vitamina C, ferro e cálcio de partes da folha de taioba (Xanthosoma sagittifolium Schott). Revista Brasileira de Agrociência, Pelotas, v. 7, n. 3, p.205-208, set/dez., 2001.

27. POLLONIO, M. A. R. Estudo das propriedades funcionais do isolado protéico obtido do resíduo industrial do processamento de tomate. Lavras-MG,1988. 171 p. Dissertação (Mestrado em Ciência de Alimentos) Universidade Federal de Lavras (UFLA).

28. REED, J. D.; McCOWELL, R. E.; VAN SOEST, P. J.; HORVATH, P. $\mathrm{J}$. Condensed tannins: a factor limiting the use of cassava forage. Journal of the Science of Food and Agriculture, London, v. 33, p. 213-220, 1982.

29. SAlGADO, J. S.; SANTOS, A. C. Estudo do concentrado protéico de folhas de mandioca, obtenção, análise química e suplementação com aminoácidos. Archivos Latinoamericanos de Nutrición, Caracas, v. 36, n. 3, p. 483-494, 1986.

30. SANGRONIS, E.; MACHADO, C.; CAVA, R. Propriedades funcionales de las harinas de leguminosas germinadas. Interciencia, Caracas, v. 29, n. 2, feb. 2004.

31. SILVA, D. J. Análise de alimentos: métodos químicos e biológicos. Viçosa: UFV, 1990. 166p.

32. TANGKA, J. K. Analysis of the thermal energy requirements for the extraction of leaf protein concentrate from some green plants. Biosystems Engineering, San Diego, v. 86, n. 4, p. 473-479, dec., 2003.

33. WANG, S. H.; CABALLERO-CORBOBA, G. M.; SGARBIERI, V. C. Propriedades funcionais de misturas de farinhas de trigo e soja-desengordurada, pré-tratada por microondas. Ciência e Tecnologia de Alimentos, Campinas, v. 12, n. 1, p. 14-25, jan/jun. 1992.

34. WOBETO, C. et al. Nutrients in the cassava (Manihot esculenta Crantz) leaf meal at three ages of the plant. Ciência e Tecnologia de Alimentos, Campinas, v. 26, n. 4, p. 865-869, out/dez. 2006. 